\title{
Revista do

\section{O PRINCÍPIO DA BOA FÉ E O PRINCÍPIO DA PROPORCIONALIDADE — O PROBLEMA DAS CLÁUSULAS ABUSIVAS NOS CONTRATOS COM OS CONSUMIDORES ENTRE DIREITO PRIVADO E DIREITO PÚBLICO}

\section{GOOD FAITH AND PROPORTIONALITY - UNFAIR TERMS IN CONSUMER CONTRACTS BETWEEN PRIVATE LAW AND PUBLIC LAW \\ Nuno Manuel Pinto Oliveira ${ }^{1}$}

\begin{abstract}
Recebido em: 14/11/2017 Aceito em: 29/12/2017

delmomattos@hotmail.com
\end{abstract}

Resumo: O acórdão do Tribunal de Justiça da União Europeia de 14 de Março de 2013, em que se sustentou que o conceito de boa fé da Directiva 1993/13/CE deveria interpretar-se como correspondendo ao princípio constitucional da proporcionalidade; ao fazê-lo, sugere que a distinção entre os limites aos poderes públicos e aos poderes privados deve ser, pelo menos parcialmente, superada.

Palavras-chave: Cláusulas Abusivas. Contratos de Adesão. Directiva 1993/13/CE. Proporcionalidade. Tribunal De Justiça Da União Europeia.

\begin{abstract}
In the judgement of 14 March 2013, the European Union Court of Justice argued that the concept of good faith in Directive 1993/13/EC is to be interpreted as an matching the principle of proportionality. In doing so, it suggested that the distinction between the limits to private and the limits to public powers are to be overcome.
\end{abstract}

Keywords: Contracts of Adhesion. Directive 1993/13/EC. European Union Court of Justice. Proporcionality. Unfair Terms.

\section{INTRODUÇÃO. OS CRITÉRIOS GERAIS DE QUALIFICAÇÃO DE UMA CLÁUSULA COMO} ABUSIVA DO ART. 3.,ㅗㄴ․1, DA DIRECTIVA 1993/13/CE, DE 5 DE ABRIL DE 1993

Os contratos de adesão sempre estiveram entre dois mundos; entre o mundo dos contratos, por que se põem a valer normas individuais, e o mundo das leis $^{2}$ e dos regulamentos ${ }^{3}$, por que se põem a valer normas gerais. Saleilles sugeria que os contratos de adesão forssem tratados como leis e Hauriou, como regulamentos . O percurso de Saleilles e de Hauriou foi retomado na França por René Demogue ${ }^{4}$ e, nos Estados Unidos, por Friederich Kessler ${ }^{5}$, por David Slawson ${ }^{6}$ e por Margaret

\footnotetext{
${ }^{1}$ Universidade do Minho - Braga - Portugal

${ }^{2}$ Raymond Saleilles, De la déclaration de volonté, F. Pichon, Paris, 1901, pág. 230.

${ }^{3}$ Apud Georges Dereux, "De la nature juridique des contrats d'adhésion", in: Revue trimestrielle de droit civil, 1910, págs. 503-541 (esp. págs. 505-506).

${ }^{4}$ René Demogue, Les notions fondamentales du droit privé. Essai critique, pour servir d'introduction à l'étude des obligations, Arthur Rousseau, Paris, 1911, pág. 573 - os contratos de adesão seri-am“[d]es règles privées agissant à la manière de lois d'Etat".
} 
Jane Radin 7 . Os contratos de adesão seriam actos legislativos, ou quase legislativos; como actos legislativos, ou quase legislativos, sujeitar-se-iam a limites. Entre os limites dos contratos de adesão estaria, ou deveria estar, o princípio da proporcionalidade.

O acórdão do Tribunal de Justiça da União Europeia 14 de Março de 2013, no processo C415/11, confirma a conveniência de uma superação das fronteiras entre o direito público e o direito privado. O Tribunal de Justiça pronunciou-se sobre a interpretação do art. $3 . \stackrel{\circ}{=}$ n. .91 , Directiva 1993/13/CEE, de 5 de Abril de 1993, relativa às cláusulas abusivas em contratos com os consumidores, cujo texto é o seguinte:

uma cláusula contratual que não tenha sido objecto de negociação individual é considerada abusiva quando, a despeito da exigência de boa fé, der origem a um desequilíbrio significativo em detrimento do consumidor, entre os direitos e [as] obrigações das partes decorrentes do contrato.

Face ao art. $3 .^{\circ}$, os critérios gerais de controlo das cláusulas contratuais "que não tenha[m] sido objecto de negociação individual" definem-se através de dois conceitos indeterminados. Em primeiro lugar, através do conceito indeterminado de boa fé e, em segundo lugar, através do conceito indeterminado de "desequilíbrio significativo, em detrimento do consumidor, entre os direitos e as obrigações das partes decorrentes do contrato"8. Entre os problemas de interpretação dos "elementos que conferem um carácter abusivo a uma cláusula contratual", encontram-se os três seguintes:

(i) Qual é a relação sistemática entre os conceitos indeterminados de boa fé e de "desequilíbrio significativo [...] entre os direitos e [as] obrigações das partes decorrentes do contrato"?

(ii) Que é um "desequilíbrio significativo [...] entre os direitos e [as] obrigações das partes decorrentes do contrato"?;

(iii) Que é um "desequilíbrio significativo [...] entre os direitos e as obrigações das partes [...], a despeito da exigência de boa fé"?

\footnotetext{
${ }^{5}$ Friedrich Kessler, "Contracts of Adhesion - Some Thoughts about Freedom of Contract", in: Columbia Law Review, vol. 43 (1943), págs. 629-642.

${ }^{6}$ W. David Slawson, "Standard Contract Terms and Democratic Control of Lawmaking Power", in: Har-vard Law Review, vol. 84 (1971), págs. 529-566 - cujos argumentos são desenvolvidos em W. David Slawson, "The New Meaning of Contracting: The Transformation of Contracts by Standard Forms", in: University of Pittsburgh Law Review, vol, 46 (1984), págs. 21-74, ou em W. David Slawson, "Contractual Discretionary Power: A Law to Prevent Deceptive Contracting by Standard Form", in: Michigan State Law Review, 2006, págs. 853-882.

7 Margaret Jane Radin, Boilerplate: The Fine Printing, Vanishing Rights, and the Rule of Law, Princeton University Press, Princeton, 2012; Margaret Jane Radin, "An Analytical Framework for Legal Evaluation of the Boilerplate", in: Gregory Klass / George Letsas / Prince Saprai (coord.), Philosophical Foundations of Contract Law, Oxford University Press, Oxford, 2014, págs. 215-237; Margaret Jane Radin, "Boilerplate: A Threat to the Rule of Law?", in: Lisa M. Austin / Dennis Klimchuk (coord.), Private Law and the Rule of Law, Oxford University Press, Oxford, 2014, págs. 288-305; Margaret Jane Radin, "The Deformation of Contract in the Information Society", in: Oxford Journal of Legal Studies, vol. 37 (2017), págs. 505-533.

${ }^{8} \mathrm{Cf}$. designadamente Hugh Collins, "Good Faith in European Contract Law", in: Oxford Journal of Legal Studies, vol. 14 (1994), págs. 229-254 (249): "[Article 3 (1)] combines two tests of unfairness: (a) the term must be contrary to the requirement of good faith; and (b) the term must cause a significant imbal-ance in the contractual obligations to the detriment of the consumer".
} 
O Tribunal de Justiça propôs-se resolver os três problemas sustentando que os conceitos de "desequilíbrio significativo" e de "desequilíbrio significativo [...] a despeito da exigência de boa fé" designam requisitos autónomos e requisitos cumulativos da qualificação de uma cláusula contratual não negociada como cláusula abusiva; que o conceito de desequilíbrio significativo remete para uma comparação entre os resultados da aplicação das normas contratuais e os resultados da aplicação das normas legais (supletivas); e que o conceito de desequilíbrio significativo a despeito da exigência de boa fé remete para duas coisas - para a conduta dos contraentes e para o conteúdo do contrato, conformado pela conduta dos contraentes. Em todos os casos em que o conceito de desequilíbrio significativo a despeito da exigência de boa fé remete para o conteúdo do contrato, o conteúdo do conceito jurídico-civilístico de boa fé coincide com o conteúdo do conceito jurídico-constitucional de proporcionalidade ${ }^{9}$. Com o conceito jurídico-civiístico de boa fé exige-se que as cláusulas contratuais por que se causa um desequilíbrio significativo em detrimento do consumidor sejam adequadas e necessárias para a satisfação de um interesse legítimo do profissional e que sejam e proporcionadas em sentido estrito, não deixando o consumidor "totalmente desprotegido perante a alteração do equilíbrio contratual a favor do profissional que se prevalece da cláusula".

\section{OS CONCEITOS INDETERMINADOS DE BOA FE E DE DESEQUILÍBRIO SIGNIFICATIVO COMO REQUISITOS AUTÓNOMOS E COMO REQUISITOS CUMULATIVOS DA QUALIFICAÇÃO DE UMA CLÁUSULA CONTRATUAL NÃO NEGOCIADA COMO CLÁUSULA ABUSIVA}

Martin Ebers diz, de uma forma impressiva, que a relação sistemática entre os dois conceitos

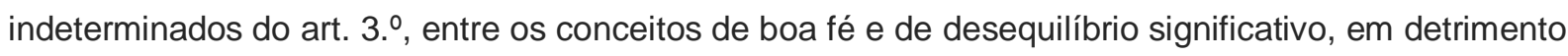
do consumidor, entre os direitos e [as] obrigações das partes decorrentes do contrato é, e sempre foi, uma relação um tanto ou quanto "obscura"10.

Em primeiro lugar, pode pensar-se que a autonomia dos dois critérios é (tão-só) uma autonomia aparente. Os dois critérios "interpenetra[r]-se[-iam] e fund[ir]-se[-iam] num único parâmetro de valoração: o desequilíbrio normativamente relevante [seria] só aquele que se coloca[sse] em contraste com a boa fé"11. Em segundo lugar, pode pensar-se que o conceito de boa fé é o critério principal e que o conceito de desequilíbrio significativo é (tão-só) um critério acessório ou secundário. $O$ requisito do desequilíbrio significativo, em detrimento do consumidor, entre os direitos e [as] obrigações das partes decorrentes do contrato seria (tão-só) um indício ou um sinal de que a cláusula contratual controvertida é uma cláusula contrária ao requisito da boa fé. Em terceiro lugar, pode

\footnotetext{
${ }^{9}$ Cf. designadamente Oliver Gerstenberg, "Constitutional Reasoning in Private Law: The Role of the CJEU in Adjudicating Unfair Terms in Consumer Contracts", in: European Law Journal, 2015, págs. 599-621.

${ }^{10}$ Martin Ebers, "La revisione del diritto europeo del consumatore: I'attuazione nei Paesi membri della direttiva sulle clausole abusive (93/13/CEE) e le prospettive d'ulteriore armonizzazione", in: Contrat-to e impresa / Europa, 2007, págs. 696-733 (710): “È da sempre oscuro, come il principio della buona fede si rapporti al criterio dello 'squilibrio'".

${ }^{11} \mathrm{Cf}$. Joaquim de Sousa Ribeiro, "A boa fé como norma de validade", in: Ars Judicandi. Estudos em homenagem ao Prof. Doutor António Castanheira Neves, vol. II, Faculdade de Direito da Universidade de Coimbra / Coimbra Editora, Coimbra, 2009, págs. 667-732 (715).
} 
pensar-se que os conceitos indeterminados de boa fé e de desequilíbrio significativo, em detrimento do consumidor, entre os direitos e [as] obrigações das partes designam requisitos alternativos e, em quarto lugar, pode pensar-se que designam requisitos cumulativos de qualificação de uma cláusula contratual não negociada como cláusula abusiva ${ }^{12}$.

O acórdão do Tribunal de Justiça de 14 de Março de 2013, no processo C-415/11 (Aziz), conforma-se com a quarta das teses descritas. A boa fé e o dese-quilíbrio significativo, em detrimento do consumidor, entre os direitos e as obrigações das partes designam requisitos cumulativos de qualificação de uma cláusula contra-tual como abusiva:

Impõe-se [...] um duplo controlo, ou um controlo em dois momentos sucessivos, distintos um do outro: apura-se, em primeiro lugar, se o conteúdo é significativamente desequilibrado, para depois ajuízar se tal viola a boa fét3.

Estando em causa dois requisitos cumulativos da qualificação de uma cláusula contratual como abusiva, os tribunais dos Estados-Membros da União Europeia devem pronunciar-se sobre duas coisas: Em primeiro lugar, os tribunais dos Estados-Membros da União Europeia devem pronunciar-se sobre se há, ou não, um desequilíbrio significativo, em detrimento do consumidor, entre os direitos e [as] obrigações das partes decorrentes do contrato e, em segundo lugar, havendo um desequilíbrio significativo, devem pronunciar-se sobre se há, ou não, um desequilíbrio "a despeito da exigência de boa fé".

\section{O REQUISITO DO "DESEQUILÍBRIO SIGNIFICATIVO [...] EM DETRIMENTO DO CONSUMIDOR"}

Em relação ao primeiro requisito, confrontavam-se duas concepções do desequilíbrio significativo - a primeira sustentava que o desequilíbrio deveria apreciar-se em termos absolutos; que o conceito de um desequilíbrio significativo, em detrimento do consumidor, entre os direitos e [as] obrigações das partes decorrentes do contrato deveria concretizar-se através de uma análise autónoma das normas contratuais, atendendo, p. ex., à sua justificação objectiva ${ }^{14}$; a segunda sustentava que o desequilíbrio deveria apreciar-se em termos relativos; que o conceito de um

\footnotetext{
${ }^{12}$ Cf. designadamente Vincenzo Roppo, "The Definition of 'Unfairness'. The Application of Articles 3 (1), 4 (1) and of the Annexes to the Directive" / "La définition du caractère abusif: I'application des articles 3, paragraphe 1, et 4, paragraphe 1, et les annexes de la directive", in: The 'Unfair Terms' Directive, Five Years On. Evaluation and Future Perspectives / La directive 'clauses abusives', cinq ans après. Évaluation et perspectives pour l'avenir, European Commission / Commission Européenne, Bruxelles, 1999, págs. 125-134 (pág. 126 do Preliminary Document e págs. 131-136 do Final Report) e págs. 135-146 (pág. 136 do Document préparatoire e págs. 142-144 do Rapport final); Paolisa Nebbia, Unfair Contract Terms in European Law. A Study in Comparative and EC Law, Hart Publishing, Oxford / Portland (Oregon), 2007, págs. 143-152; Martin Ebers, "La revisione del diritto europeo del consuma-tore: I'attuazione nei Paesi membri della direttiva sulle clausole abusive (93/13/CEE) e le prospettive d'ulteriore armonizzazione", cit., págs. 709-710.

${ }^{13} \mathrm{Cf}$. Joaquim de Sousa Ribeiro, "A boa fé como norma de validade", cit, pág. 713.

${ }^{14}$ Cf. designadamente Karl Riesenhuber, Europäisches Vertragsrecht, 2. ed., de Gruyter, Berlin, 2006, pág. 265: $O$ aplicador do direito deveria atender à unilateralidade dos direitos e dos deveres constituídos pelas normas contratuais e, no caso de não haver unilateralidade, à justificação objectiva dos direitos e dos deveres atribuídos ao consumidor.
} 
O princípio da boa fé e o princípio da proporcionalidade - o problema das cláusulas abusivas nos contratos com os

desequilíbrio significativo deveria concretizar-se de uma análise comparativa das normas contratuais e das normas legais (supletivas).

A advogada-geral Julianne Kokott caracterizava o "desequilíbrio significativo [...] entre os direitos e [as] obrigações das partes" como uma diferença (como uma diferença significativa?) entre os direitos e os deveres das partes que decorreriam da aplicação das normas contratuais e os direitos e os deveres que decorreriam da aplicação das normas legais (supletivas). Ora, como as normas legais supletivas constam da legislação nacional (= da legislação dos Estados-Membros da União Europeia), a advogada-geral fala de uma comparação entre a cláusula contratuais e a "legislação nacional aplicável, se as próprias partes não tiverem acordado um regime contratual": "A questão de saber se uma cláusula [contratual] dá origem a um desequilíbrio significativo, em detrimento do consumidor, dos direitos e obrigações das partes decorrentes do contrato não pode ser apreciada sem uma comparação com a legislação nacional aplicável, se as próprias partes não tiverem acordado um regime contratual." ${ }^{\text {1516. }}$. O Tribunal de Justiça acolheu, sem adaptações ou modificações significativas, os critérios da advogada-geral Kokott:

para saber se uma cláusula cria, em detrimento do consumidor, um 'desequilíbrio significativo' entre os direitos e as obrigações das partes decorrentes do contrato, há que ter em conta, designadamente, as normas de direito nacional aplicáveis na falta de acordo das partes nesse sentido. ${ }^{171819}$

O aplicador do direito deverá perguntar-se quais são os direitos e os deveres que decorrem da aplicação das cláusulas contratuais e quais são os direitos e os deveres que decorreriam da

\footnotetext{
${ }^{15}$ Conclusões da advogada-geral Julianne Kokott no processo C-415/11 (Aziz) - n.. 71 .

${ }^{16} \mathrm{O}$ conceito de boa fé, concretizando-se, como o Tribunal de Justiça considera que deve concretizar-se, através da "análise comparativa" entre as normas contratuais e as normas legais dispositivas ou supletivas, converte-se em critério impróprio para a aproximação ou harmonização dos direitos (dos sistemas jurídicos) dos Estados-membros da União Europeia [cf. Gianmaria Ajani / Martin Ebers, "Introduction", in: Gianmaria Ajani / Martin Ebers (coord.), Uniform Terminology for European Private Law, Nomos, Baden Baden, 2005, págs. 11-20 (13): "Although the Unfair Contract Terms Directive appears prima facie to introduce a consistently applicable criterion for the general clause 'good faith' to review contractual terms, the content of this vague notion can and will remain different from Member State to Member State"].

${ }^{17}$ Acórdão do Tribunal de Justiça de 14 de Março de 2013, no processo C-415/11 (Aziz) - n.o 68.

${ }^{18}$ O Tribunal de Justiça acrescenta, contudo, o seguinte: "afigura-se pertinente, para este efeito [ou seja: para a apreciação do 'desequilíbrio significativo', proceder a um exame da situação jurídica em que se encontra o referido consumidor, atendendo aos meios de que dispõe, ao abrigo da legis-lação nacional, para pôr termo à utilização de cláusulas abusivas" (n.o 68). Concordando com as conclusões da advogada-geral (em particular, com a conclusão apresentada sob o n.. 68), dis-cordamos dos argumentos deduzidos no acórdão: 0 "exame da situação jurídica em que se encontra o referido consumidor, atendendo aos meios de que dispõe [...] para pôr termo à utilização de cláusulas abusivas", deverá relacionar-se exclusivamente com a apreciação do segundo requisito ("a despeito da exigência de boa fé")

${ }^{19}$ Criticando a tese de que o conceito de desequilíbrio significativo exige a comparação entre as normas contratuais e as normas legais (supletivas) dos Estados-membros, com o argumento de que põe em causa a concepção da cláusula geral do art. 3., n. 1, da Directiva 1993/13/CE como uma "cláusula geral conformada autonomamente pelo direito comunitário" (gemeinschaftsautonome Generalklausel), Karl Riesenhuber, Europäisches Vertragsrecht, cit., págs. 259-261.
} 
aplicação das normas legais ${ }^{20}$. Caso haja uma diferença significativa entre a situação em que as normas contratuais colocam o consumidor e a situação em que as normas legais o colocariam, haverá um indício de um desequilíbrio significativo²1.

O índicio pode ser confirmado ou infirmado pelo contexto constituído por todas as cláusulas do contrato e por todas as cláusulas dos contratos coligados ${ }^{22}$. O desequilíbrio significativo, desfavorável ao consumidor, decorrente de uma determinada cláusula pode ser compensado por desequilíbrios significativos, favoráveis ao consumidor, decorrentes das demais cláusulas do contrato e / ou das cláusulas dos demais contratos ${ }^{23}$.

Entre os casos paradigmáticos de compensação de desequilíbrios signifcativos desfavoráveis ao consumidor estão as cláusulas de redução do preço. Os considerandos da Directiva 1993/13/CE dizem-nos que "o objecto principal do contrato e a relação qualidade/preço podem [...] ser considerados na apreciação do carácter abusivo de outras cláusulas": "[...] desse facto decorre, inter alia, que, no caso de contratos de seguros, as cláusulas que definem ou delimitam claramente o risco segurado e o compromisso do segurador não são objecto de tal apreciação [do carácter abusivo] desde que essas limitações sejam tidas em conta no cálculo do prémio a pagar pelo consumidor". Os tribunais deverão atender à circunstância de que um desequilíbrio significativo, em detrimento do consumidor, entre os direitos e os deveres das partes decorrentes do contrato pode ser compensado por uma redução da contraprestação (p. ex., do preço $)^{24}$.

\section{O REQUISITO DO “DESEQUILÍBRIO SIGNIFICATIVO [...] A DESPEITO DA EXIGÊNCIA DE BOA FÉ”,}

Em relação ao segundo requisito, confrontavam-se duas concepções da boa fé25.

\footnotetext{
${ }^{20}$ Acórdão do Tribunal de Justiça de 14 de Março de 2013, no processo C-415/11 (Aziz) - n.o 68: “É através de uma análise comparativa deste tipo que o órgão jurisdicional nacional poderá avaliar se e em que medida o contrato coloca o consumidor numa situação menos favorável do que a prevista no direito nacional em vigor".

${ }^{21}$ Cf. designadamente Stefan Grundmann, "The General Clause or Standard in EC Contract Law Directivas - A Survey on Some Important Legal Measures and Aspects in EC Law", in: Stefan Grundmann / Denis Mazeaud (coord.), General Clauses and Standards in European Contract Law, Kluwer Law International, The Hague, 2006, págs. 141-161 (145) - "The most important element in value judgements (abuse of rights!) is where the party setting the standard terms deviates considerably from default rules..." -, ou Horst Eidenmüller / Florian Faust / Hans Christoph Grigoleit / Nils Jansen / Gerhard Wagner / Reinhard Zimmermann, "Towards a Revision of the Consumer-acquis" (2011), in: WWW: < http://papers.ssrn.com/sol3/papers.cfm?abstract_id=1807943 >, pág. 13.

${ }^{22}$ Cf. art. 4.o, n.o 1, da Directiva 1993/13/CEE, de 5 de Abril de 1993.

${ }^{23}$ Hugh Collins, "Good Faith in European Contract Law", cit., pág. 249: "The question which the court must address is whether or not the exclusions, qualifications, and limitations on the trader's obligations are balanced in the contract by either similar limitations favouring the consumer or a commensurate reduction in the price." ${ }^{24}$ Cf. Hugh Collins, "Good Faith in European Contract Law", cit., pág. 249; Stefan Grundmann, "The General Clause or Standard in EC Contract Law Directivas - A Survey on Some Important Legal Measures and Aspects in EC Law", cit., pág. 145: The most important element in value judgements [...] is where the party setting the standard terms deviates considerably from default rules without giv-ing compensation for doing so, instead of just moderately adopting the default rules to meet the particu-lar needs of the relevant sector of business".

${ }^{25}$ Sobre o conceito indeterminado de boa fé, vide desenvolvidamente António Menezes Cordeiro, Da boa fé no direito civil, Livraria Almedina, Coimbra, 1997 (reimpressão).
} 
O princípio da boa fé e o princípio da proporcionalidade - o problema das cláusulas abusivas nos contratos com os consumidores entre direito privado e direito público

Como o conceito indeterminados de boa fé pode relacionar-se com a conduta dos

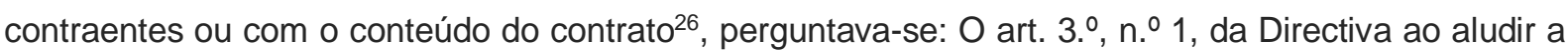
um desequilíbrio significativo, em detrimento do consumidor, a despeito da exigência da boa fé, estará a dar ao princípio da boa fé só o sentido de uma norma sobre a conduta dos contraentes, estará a dar-lhe só o sentido de uma norma sobre o conteúdo do contrato ou estará a dar-Ihe, simultaneamente, os dois sentidos?

A advogada-geral Julianne Kokott afirmava que o conceito indeterminado de boa fé exigia uma análise comparativa entre uma situação real e uma situação hipo-tética; entre as cláusulas contratuais que foram aceites pelo consumidor na situ-ação real e as cláusulas contratuais que teriam sido aceites pelo consumidor numa situação hipotética — que teriam sido aceites "no âmbito de uma negociação indi-vidual do contrato" —:

Um desequilíbrio significativo é considerado não justificado em particular quando os direitos e obrigações do consumidor são limitados numa me-dida tal que a parte que impõe as condições contratuais não possa pre-sumir, de boa-fé, que o consumidor aceit[aria] essas disposições no âm-bito de uma negociação individual do contrato ${ }^{27}$.

O acórdão do Tribunal de Justiça de 14 de Março de 2013 acolhe o critério da advogada-geral Julianne Kokott, com uma adaptação ou modificação muito significativa.

Enquanto a advogada-geral Kokott não faz qualquer alusão directa ao com-portamento do profissional, o Tribunal de Justiça fá-la. O Tribunal de Justiça faz uma alusão ao facto de que o profissional deve "tratar de forma leal e equitativa com o consumidor":

No que respeita ao facto de saber em que circunstâncias foi criado esse desequilíbrio 'a despeito da exigência de boa-fé', importa declarar que, atendendo ao décimo sexto considerando da diretiva e conforme sublinhou a advogada-geral, no essencial, no n. $^{\circ} 74$ das suas conclusões, o tribunal nacional deve verificar, para o efeito, se o profissional, ao tratar de forma leal e equitativa com o consumidor, podia razoavelmente esperar que ele aceitaria essa cláusula, na sequência de uma negociação individual'28.

Entre as duas fórmulas há diferenças de forma e diferenças de fundo:

O critério da advogada-geral pressupõe que o princípio da boa fé do art. $3 . \stackrel{\circ}{\text {, n. }} \stackrel{0}{1}$, da Directiva 1993/13/CEE seja uma norma sobre o conteúdo do contrato. O critério do Tribunal de Justiça, esse, pressupõe que o princípio da boa fé do art. 3.ำ n.ำ 1, da Directiva 1993/13/CEE seja, simultaneamente, uma norma sobre a conduta dos contraentes e uma norma sobre o conteúdo do contrato. O desequilíbrio signifi-cativo, em detrimento do consumidor, pode ser contra a boa fé por uma de duas causas: Em primeiro lugar, o desequilíbrio significativo, em detrimento do consumidor,

\footnotetext{
${ }^{26}$ Cf. Nuno Manuel Pinto Oliveira, Princípios de direito dos contratos, Coimbra Editora, Coimbra, 2011, págs. 161-194; e, para o direito europeu dos contratos, Bénédicte Fauvarque-Cosson / Denis Mazeaud (coord.), com a colaboração de Jean-Baptiste Racine / Laura Sautonie-Laguionie / Aline Tenenbaum / Guillaume Wicker, European Contract Law - Materials for a Common Frame of Refer-ence: Terminology, Guiding Principles, Model Rules, Sellier - European Law Publishers, Munich, 2008, págs. 150-202.

${ }^{27}$ Conclusões da advogada-geral Julianne Kokott no processo C-415/11 (Aziz) - n.o 74.

${ }^{28}$ Acórdão do Tribunal de Justiça de 14 de Março de 2013, no processo C-415/11 (Aziz) - n. 74.
} 
pode ser contra a boa fé por causa da conduta do profissional - o profissional tinha o dever de tratar "de forma leal e equitativa com o consumidor", e não o cumpriu - e, em segundo lugar, o desequilíbrio significativo pode ser contra a boa fé por causa do conteúdo do contrato.

\section{O PRINCÍPIO DA BOA FÉ COMO NORMA SOBRE A CONDUTA DOS CONTRAENTES [= SOBRE O PROCEDIMENTO DE (CON)FORMAÇÃO DO CONTEÚDO DO CONTRATO]}

Em primeiro lugar, os tribunais dos Estados-Membros devem apreciar a conduta do profissional no procedimento de (con)formação do conteúdo do contrato.

O acórdão do Tribunal de Justiça de 15 de Março de 2012, no processo C-453/10 (Perenicova) acentua que o art. $4 .^{\circ}$, n. $^{\circ} 1$, da Directiva 1993/13/CEE "define de forma particularmente ampla os critérios que permitem efetuar [a] apreciação [do carácter abusivo das cláusulas], abrangendo expressamente 'todas as circunstâncias' que rodeiam a celebração do contrato em causa"29 ${ }^{30}$. Entre as circunstâncias relevantes no sentido do art. 4.. , ก. .9 1, encontrar-se-iam, designadamente, a constatação de que o profissional não cumpriu o dever de transparência do art. 5. - da Di-rectiva 1993/13/CEE ${ }^{31}$, de que o procedimento de (con)formação do conteúdo do contrato corresponde a uma prática comercial agressiva, no sentido dos arts. 5.. e 8.. da Directiva 2005/29/CE, ou de que o procedimento de conformação do conteúdo do contrato corresponde a uma prática comercial enganosa, no sentido dos arts. 5.ำ 6.ํ e $7^{\circ}$ da Directiva 2005/29/CE:

a constatação do caráter desleal de uma prática comercial constitui um elemento, entre outros, em que o juiz competente se pode basear para apreciar o caráter abusivo das cláusulas de um contrato nos termos do artigo $4 .^{\circ}$, n. $^{\circ} 1$, da Diretiva 93/13. ${ }^{32} 33$

\footnotetext{
${ }^{29}$ Acórdão do Tribunal de Justiça 15 de Março de 2012, no processo C-453/10 (Perenicova) - n.o 42.

${ }^{30}$ Criticando o conceito de cláusula abusiva dos arts. 3.o, n.o 1, e 4.ํ, n.․ 1, da Directiva 1993/13/CE, de 5 de Abril de 1993, por causa da sua sensibilidade a "todas as circunstâncias que, no momento em que [o contrato] foi celebrado, rodearam a sua conclusão" e, em particular, ao comportamento dos contraentes no procedimento de (con)formação do conteúdo do contrato, Horst Eidenmüller / Florian Faust / Hans Christoph Grigoleit / Nils Jansen / Gerhard Wagner / Reinhard Zimmermann, "Towards a Revision of the Consumeracquis" (2011), in: WWW: < http://papers.ssrn.com/sol3/papers.cfm?abstract_id=1807943 >, pág. 14.

31 Cf. designadamente Karl Riesenhuber, Europäisches Vertragsrecht, cit., pág. 268. - O raciocínio é confirmado pelo art. 83., n.ㅇ 2, da Proposta de regulamento do Parlamento Europeu e do Conselho relativo a um direito europeu comum da compra e venda: O carácter abusivo de uma cláusula contra-tual deve ser apreciado mediante consideração da circunstância de a cláusula ter sido redigida de forma clara e compreensível.

${ }^{32}$ Acórdão do Tribunal de Justiça 15 de Março de 2012, no processo C-453/10 (Perenicova) - n.o 43.

33 O Tribunal de Justiça distingue a influência directa e a influência indirecta da constatação do carácter desleal de uma prática comercial sobre a apreciação do carácter abusivo da cláusula contratual não negociada: (i) a influência directa consistiria em que a constatação do carácter desleal de uma prática comercial "demonstrar[ia] automaticamente e por si só o caráter abusivo das cláusulas controver-tidas"; (ii) a influência indirecta, em que a "constatação" do carácter desleal de uma prática comercial não o demonstraria "automaticamente e por si só o caráter abusivo das cláusulas controvertidas". O Tribunal de Justiça rejeita a tese da influência directa, deduzindo dois argumentos. Em primeiro lugar, o argumento de que a tese da influência directa conflitua com os arts. 3.․, n.ㅇ 1, e 4.ํ, n.ㅇ 1, da Direc-tiva 1993/13/CE. Os tribunais dos Estados-Membros deveriam pronunciar-se sobre o preenchimento dos dois requisitos do art. 3.․, n.․ 1, "em função de todas as circunstâncias próprias do caso con-creto" [cf. acórdão de 15 de Março de 2012, no processo C-453/10 (Perenicova) - n.ㅇ 44]. Em se-gundo lugar, o argumento de que a tese da influência directa
} 


\section{O PRINCÍPIO DA BOA FÉ COMO NORMA SOBRE A CONTEÚDO DO CONTRATO SOBRE OS RESULTADOS DO PROCEDIMENTO DE (CON)FORMAÇÃO DO CONTEÚDO DO CONTRATO]}

Em segundo lugar, abstraindo da conduta dos contraentes - designadamente, da conduta do profissional —, o aplicador do direito deverá apreciar o conteúdo do contrato, perguntando-se: 0 profissional "podia razoavel-mente esperar que [o consumidor] aceita[sse] [a] cláusula [controvertida], na se-quência de uma negociação individual'”?

A advogada-geral Julianne Kokott afirmava que os tribunais dos Estados-Membros deviam atender, designadamente, aos elementos seguintes:

se as cláusulas contratuais em questão são habituais, ou seja, se são utilizadas regularmente no tráfego jurídico em contratos semelhantes, ou se, pelo contrário, são ocasionais; se existe um motivo objetivo para essa cláusula contratual ou se o consumidor não fica totalmente desprotegido perante a alteração do equilíbrio contratual a favor do profissional que se prevalece da cláusula, tendo em conta o objetivo da mesma. ${ }^{34}$

Quando afirma que os tribunais dos Estados-Membros devem averiguar se há uma justificação objectiva ou uma motivação objectiva para a cláusula controvertida, a advogada-geral Kokott está a dizer que os tribunais nacionais devem fazer um (algum) controlo dos fins; quando afirma que os tribunais nacionais devem averiguar "se as cláusulas contratuais em questão são habituais [...] ou se, pelo contrário, são ocasionais" e "se o consumidor não fica totalmente desprotegido [...]", está a afirmar que os tribunais dos Estados-Membros devem fazer um (algum) con-trolo dos meios.

(1.ํ) Em primeiro lugar, a cláusula contratual não negociada deverá ser um meio adequado para a realização ou satisfação de um interesse legítimo das partes — faltando a adequação, falta um "motivo objectivo" para a cláusula controvertida.

(2.ํ) Em segundo lugar, a cláusula contratual não negociada deverá ser um meio proporcionado, designadamente, por não deixar o consumidor "totalmente desprotegido perante a alteração do equilíbrio contratual a favor do profissional que se prevalece da cláusula". Entre os indícios de que uma cláusula contratual "que não tenha sido objecto de negociação individual" é ainda proporcionada encontrar-se-á a circunstância de se tratar de uma cláusula habitual, "utilizada[] regularmente no tráfego jurídico em contratos semelhantes"; entre os indícios de que a cláusula é já desproporcionada ou excessiva encontrar-se-á a circunstância de se tratar de uma cláusula ocasional.

conflitua com o art. 3.o, n.. 2, da Direc-tiva 2005/29/CE: “A presente directiva não prejudica o direito contratual e, em particular, as normas relativas à validade,

${ }^{34}$ Conclusões da advogada-geral Julianne Kokott no processo C-415/11 (Aziz) - n.. 75. 
O Tribunal de Justiça da União Europeia completou os critérios propostos pela advogadageral Julianne Kokott, sustentando que a cláusula controvertida não deverá ultrapassar o que é necessário para atingir o fim legítimo prosseguido pelo profissional ${ }^{35} 36$.

Combinando os critérios propostos pela advogada-geral Julianne Kokott e pelo Tribunal de Justiça conclui-se que a cláusula contratual que não tenha sido objecto de uma negociação individual carece de um controlo de proporcionalidade: em primeiro lugar, deve ser um meio adequado para a realização ou satisfação de um interesse legítimo do profissional; em segundo lugar, deve ser um meio necessário para a realização ou satisfação de um interesse legítimo e, em terceiro e último lugar - last but not least —, deve ser um meio proporcionado em sentido estrito. Entre os critérios relevantes para a apreciação da proporcionalidade em sentido estrito encontrar-se-ão, em primeiro lugar, a compatibilidade das cláusulas contratuais que não tenham sido objecto de negociação individual com o fim específico do contrato e, em segundo lugar, a compatibilidade das cláusulas contratuais que não tenham sido objecto de negociação individual com os fins gerais (= com as valorações) do direito europeu dos contratos ${ }^{37}$.

\section{O PRINCÍPIO DA BOA FÉ COMO NORMA DE PROTECÇÃO DE INTERESSES LEGÍTIMOS DO PROFISSIONAL}

O resultado sustentado pelo Tribunal de Justiça é de alguma forma surpreendente.

Em conferência realizada em $1999^{38}$, a Comissão Europeia, através da Direcção-Geral da Saúde e dos Consumidores, rejeitava a tese de que uma cláusula contratual não negociada causadora de um desequilíbrio significativo, em detrimento do consumidor, pudesse ser explicada ou justificada pela sua conformidade com a boa fé:

Para a Direcção-Geral da Saúde e dos Consumidores, uma cláusula afectada por um desequilíbrio significativo [seria] sempre - automática e necessariamente, por definição - contrária à boa fé ; não poderia, por isso, ser considerada como não abusiva. ${ }^{39} 40$

\footnotetext{
${ }^{35}$ Acórdão do Tribunal de Justiça de 14 de Março de 2013, no processo C-415/11 (Aziz) - n.o 74.

${ }^{36}$ Concordando com a aplicação do princípio da proporcionalidade, na sua tripla exigência de adequação (a um "interesse legítimo"), de necessidade e de proporcionalidade em sentido estrito, Karl Riesenhuber, Europäisches Vertragsrecht, cit., pág. 266.

37 Entre os princípios concretizadores dos fins gerais (das "valorações") do direito europeu dos contratos encontrar-se-ão, designdamente, o "princípio do acordo" (Einigungsgrundsatz), o "princípio do equilíbrio" (Gleichgewichtgedanke), a protecção da confiança contratual (Schutz des vertraglichen Vertrauens), a protecção da relação de equivalência contratual (Schutz des vereibarten Äquivalenzverhältnis) e o princípio da protecção jurídica efectiva (Grundsatz des effektiven Rechtsshutzes) - Karl Riesenhuber, Europäisches Vertragsrecht, cit., pág. 265-270.

${ }^{38}$ Cujas actas constam do livro AA. VV., The 'Unfair Terms' Directive, Five Years On. Evaluation and Future Perspectives / La directive 'clauses abusives', cinq ans après. Évaluation et perspectives pour l'avenir, European Commission / Commission Européenne, Bruxelles, 1999.

39 Cf. Vincenzo Roppo, "La définition du caractère abusif: l'application des articles 3, paragraphe 1, et 4, paragraphe 1, et les annexes de la directive", cit., pág. 143.

40 Concordando com o argumento deduzido, cf. designadamente Joaquim de Sousa Ribeiro, "A boa fé como norma de validade", cit, pág. 713.
} 
Roppo dava aos argumentos deduzidos pela Direcção-Geral um alcance essencial ou exclusivamente político ("claramente político"): com a rejeição da tese de que uma cláusula causadora de um desequilíbrio significativo, em derimento do consumidor, pudesse ser explicada ou justificada pela sua conformidade com a boa fé, estar-se-ia a rejeitar que o critério da boa fé reduzisse (pudesse reduzir) a protecção dos consumidores. O perigo, que a Direcção Geral pretenderia prevenir, seria precisamente "o perigo de o critério da boa fé se tornar potencialmente lesivo para os consumidores, fazendo diminuir o nível de protecção que Ihes era proporcionado"41.

Ora o raciocínio sustentado pelo Tribunal de Justiça significa uma aceitação do perigo. Como diz, de forma paradigmática, a advogada-geral Julianne Kokott, com a distinção entre o primeiro requisito ("desequilíbrio significativo, em detrimento do consumidor, entre os direitos e [as] obrigações das partes decorrentes do contrato") e o segundo requisito ("a despeito da exigência de boa fé"), "garante-se o princípio da liberdade contratual"42. O problema está em que o princípio da liberdade contratual, quando aplicado no contexto de relações económicas e sociais de igualdade, seria uma competência, um direito ou uma faculdade de todos os sujeitos da relação jurídica; quando aplicado no contexto de relações económicas e sociais de desigualdade, seria uma competência, um direito ou uma faculdade de algum, ou de alguns; seria, portanto, um privilégio unilateral ${ }^{43}$.

Considerando, como deve considerar-se, que o princípio da liberdade contratual designa exclusivamente uma liberdade do profissional, o reconhecimento de que "que as partes possuem frequentemente um interesse legítimo numa con-figuração das suas relações contratuais diferente da lei"44, corrsponde ao reconhecimento de que que o profissional, que só o profissional, possui frequentemente um "interesse legítimo numa configuração das suas relações contra-tuais diferente da lei". O resultado só pode sufragar-se desde que se sustente que o particular poder de facto reconhecido ao profissional deve ser compensado por uma sujeição, de facto e de direito, a particulares restrições.

\section{CONCLUSÃO. O PARADIGMA DO EQUILÍBRIO JUSTO NA DIRECTIVA 1993/13/CE, DE 5 DE ABRIL DE 1993}

Face à interpretação do conceito indeterminado de boa fé consignada no acórdão do Tribunal de Justiça da União Europeia de 14 de Março de 2013, o art. 3.ำ n.ำ 1, da Directiva 1993/13/CE, de 5 de Abril de 1993, exprime um modelo ou um paradigma de equilíbrio justo entre os interesses do consumidor e os interesses do profissional.

O desequilíbrio significativo, em detrimento do consumidor, entre os direitos e [as] obrigações das partes decorrentes do contrato, altera o plano de atribuição / de distribuição dos direitos e dos deveres das partes consignado nas normas legais. $O$ equilíbrio entre os direitos e os deveres das

\footnotetext{
${ }^{41}$ Vincenzo Roppo, "The Definition of 'Unfairness'. The Application of Articles 3 (1), 4 (1) - and of the Annexes to the Directive" / "La définition du caractère abusif: I'application des articles 3, paragraphe 1, et 4, paragraphe 1, et les annexes de la directive", cit., págs. 132 e 143.

${ }^{42} \mathrm{Cf}$. conclusões da advogada-geral Julianne Kokott no processo C-415/11 (Aziz) - n.o 73.

${ }^{43} \mathrm{Cf}$. designadamente Friedrich Kessler, "Contracts of Adhesion - Some Thoughts about Freedom of Contract", cit., pág. 640.

${ }^{44} \mathrm{Cf}$. conclusões da advogada-geral Julianne Kokott no processo C-415/11 (Aziz) - n.․ 73.
} 
partes desloca-se do modelo traçado pelas normas gerais, feitas pelo legislador, para o modelo das normas individuais feitas pelas partes - nos contratos negociados - ou, pelo menos, por uma das partes - nos contratos não negociados (contratos de adesão). Ora a deslocação do equilíbrio contratual poderia ser justificada ou poderia ser injustificada: poderia ser justificada, por representar um meio adequado e necessário para realizar ou satisfazer "um interesse legítimo [das partes] numa configuração das suas relações contratuais diferente da lei" ${ }^{45}$, ou poderia ser injustificada, por não o representar. O termo "a despeito da exigência da boa fé" designaria (exclusivamente) uma deslocação injustificada. O Tribunal de Justiça, ao aceitar as conclusões da advogada-geral, está a substituir a representação da Directiva 1993/13/CE como direito discriminatório, dirigido aos consumidores, para os preferir, pela representação da Directiva 1993/13/CE, como direito não discriminatório. Os interesses dos consumidores só precisam de ser protegidos e os interesses dos profissionais só precisam de ser desprotegidos desde que o particular poder de facto do profissional seja actuado ou exercido para prosseguir um fim ilegítimo ou desde que seja exercido para prosseguir um fim legítimo por um meio ilegítimo (injustificado).

O Tribunal de Justiça da União Europeia propõe que o controlo do conteúdo dos actos de direito privado seja feito através da remissão para um princípio conformado pelo direito público. Entre os critérios de direito privado relevantes para a qualificação dos meios como legítimos ou como ilegítimos encontra-se o princípio da proporcionalidade. Com a sua remissão, explícita ou implícita, para o princípio da proporcionalidade, o Tribunal de Justiça sugere uma superação das fronteiras entre o direito privado e o direito público. O princípio da proporcionalidade seria um princípio geral de restrição do poder - aplicar-se-ia às relações desequilibradas, às relações de poder, típicas do direito público e deveria aplicar-se às relações desequilibradas, de poder típicas do direito privado.

\section{REFERÊNCIAS}

COLLINS, Hugh, "Good Faith in European Contract Law", in: Oxford Journal of Legal Studies, vol. 14 (1994), págs. 229-254 (249).

CORDEIRO, António Menezes. Da boa fé no direito civil, Livraria Almedina, Coimbra, 1997.

DEMOGUE, René, Les notions fondamentales du droit privé. Essai critique, pour servir d'introduction à l'étude des obligations, Arthur Rousseau, Paris, 1911.

EBERS, Martin, "La revisione del diritto europeo del consumatore: l'attuazione nei Paesi membri della direttiva sulle clausole abusive (93/13/CEE) e le prospettive d'ulteriore armonizzazione", in: Contratto e impresa / Europa, 2007, págs. 696-733 (710).

European Commission. The 'Unfair Terms' Directive, Five Years On. Evaluation and Future Perspectives / La directive 'clauses abusives', cinq ans après. Évaluation et perspectives pour l'avenir, Bruxelles, 1999.

GERSTENBERG, Oliver, "Constitutional Reasoning in Private Law: The Role of the CJEU in Adjudicating Unfair Terms in Consumer Contracts", in: European Law Journal, 2015, págs. 599-621.

GRUNDMANN, Stefan, "The General Clause or Standard in EC Contract Law Directivas - A Survey on Some Important Legal Measures and Aspects in EC Law", in: Stefan Grundmann / Denis Mazeaud

\footnotetext{
${ }^{45} \mathrm{Cf}$. conclusões da advogada-geral Julianne Kokott no processo C-415/11 (Aziz) - n. 73.
} 
O princípio da boa fé e o princípio da proporcionalidade - o problema das cláusulas abusivas nos contratos com os

(coord.), General Clauses and Standards in European Contract Law, Kluwer Law International, The Hague, 2006.

KESSLER, Friedrich, "Contracts of Adhesion - Some Thoughts about Freedom of Contract", in: Columbia Law Review, vol. 43 (1943).

NEBBIA, Paolisa, Unfair Contract Terms in European Law. A Study in Comparative and EC Law, Hart Publishing, Oxford / Portland (Oregon), 2007, págs. 143-152.

OLIVEIRA, Nuno Manuel Pinto. Princípios de direito dos contratos, Coimbra Editora, Coimbra, 2011.

RADIN, Margaret Jane, "An Analytical Framework for Legal Evaluation of the Boilerplate", in: Gregory Klass / George Letsas / Prince Saprai (coord.), Philosophical Foundations of Contract Law, Oxford University Press, Oxford, 2014, págs. 215-237.

"Boilerplate: A Threat to the Rule of Law?", in: Lisa M. Austin / Dennis Klimchuk (coord.), Private Law and the Rule of Law, Oxford University Press, Oxford, 2014, págs. 288-305.

"The Deformation of Contract in the Information Society", in: Oxford Journal of Legal Studies, vol. 37 (2017), págs. 505-533.

. Boilerplate: The Fine Printing, Vanishing Rights, and the Rule of Law, Princeton University Press, Princeton, 2012.

RIBEIRO, Joaquim de Sousa, "A boa fé como norma de validade", in: Ars Judicandi. Estudos em homenagem ao Prof. Doutor António Castanheira Neves, vol. II, Fac-uldade de Direito da Universidade de Coimbra / Coimbra Editora, Coimbra, 2009, págs. 667-732.

RIESENHUBER, Karl, Europäisches Vertragsrecht, 2. ㄹ ed., de Gruyter, Berlin, 2006.

SLAWSON, W. David, "Standard Contract Terms and Democratic Control of Law-making Power", in: Harvard Law Review, vol. 84 (1971).

\section{COMO CITAR ESSE DOCUMENTO:}

PINTO OLIVEIRA, Nuno Manuel. O princípio da boa fé e o princípio da proporcionalidade - o problema das cláusulas abusivas nos contratos com os consumidores entre direito privado e direito público. Revista do Direito, Santa Cruz do Sul, v. 3, n. 53, dez. 2017. ISSN 1982-9957. Disponível em: <https://online.unisc.br/seer/index.php/direito/article/view/11326>. Acesso em: doi:http://dx.doi.org/10.17058/rdunisc.v3i53.11326. 